\title{
El uso preventivo de paracetamol reduciría la inmunogenicidad postvacunal
}

\author{
Prophylactic paracetamol administration at time of vaccination seems to reduce antibody responses \\ Prymula R y col. Lancet 2009;374:1339-50
}

Objetivo

Evaluar el efecto preventivo del paracetamol en la reducción de episodios febriles luego de la vacunación y también su efecto sobre la inmunogenicidad.

\section{Diseño}

Ensayo clínico aleatorizado y abierto* (para la vacuna y para el refuerzo).

\section{Lugar}

Estudio multicéntrico realizado en diez centros en la Republica Checa.

\section{Pacientes}

459 niños sanos de nueve a 16 semanas de edad al momento del enrolamiento (primera dosis de vacuna) y con 12 a 15 meses al momento del refuerzo.

\section{Intervención}

Los niños se asignaron aleatoriamente al grupo paracetamol (GP) que recibía tres dosis diarias de paracetamol durante las primeras 24 horas post-vacunación y el grupo control (GC) que no recibía dicha profilaxis. La vacuna antineumocóccica decavalente conjugada con proteína $D$ de Haemophilus influenzae no tipeable y vacuna séxtuple (contra Haemophilus influenzae Tipo B [Hib], Difteria, Tétanos, Pertussis acelular, Poliomielitis inactivada y Hepatitis B) era administrada a todos los participantes a los tres, cuatro y cinco meses de edad y la vacuna antirotavirus, a los tres y cuatro meses. Se aplicaron refuerzos de las dos primeras vacunas a los 12 a 15 meses de edad respetando la aleatorización inicial con respecto a la administración de profilaxis o no con paracetamol.

\section{Medición de resultados principales}

El resultado principal fue la reducción de episodios febriles (mayor a $38^{\circ} \mathrm{C}$ ) durante los tres días posteriores a la vacunación y el secundario, la inmunogenicidad resultante de cada vacunación según el esquema antipirético.

\section{Resultados principales}

El porcentaje de niños con temperatura mayor a $38^{\circ} \mathrm{C}$ fue significativamente menor en el GP que en el GC (ver tabla 1). No hubo diferencias entre ambos grupos para temperaturas mayores a $39,5^{\circ} \mathrm{C}$ (incidencia menor a $1 \%$ en ambos grupos). La concentración media geométrica de anticuerpos fue significativamente menor en el GP después de la vacunación primaria para todos los serotipos de la vacuna antineumocóccica, antidiftérica, antitetánica y antipertusis. Esta disminución se mantuvo de forma significativa luego del refuerzo al año.

Tabla 1. Resultados del paracetamol preventivo vs. control

\begin{tabular}{|c|c|c|c|c|}
\hline \multicolumn{2}{|c|}{ Resultados } & Paracetamol & Control & RRA $^{\star}$ (IC95\%) \\
\hline \multirow{2}{*}{$\begin{array}{l}\text { Temperatura } \\
\text { mayor } \\
\text { a } 38^{\circ} \mathrm{C}\end{array}$} & $\begin{array}{c}\text { Vacunación } \\
\text { primaria }\end{array}$ & $94 / 226(42 \%)$ & 154/233 (66\%) & $24,5 \%(15,5$ a 33,1$)$ \\
\hline & Refuerzo & $64 / 178(36 \%)$ & 100/172 (58\%) & $22,2 \%(11,8$ a 32,1$)$ \\
\hline \multicolumn{2}{|l|}{ cuerpos } & $85(873$ a 1112 & 699 (1435 a 1783 & \\
\hline
\end{tabular}

\#Unidades ELISA/ml (IC95\%) anti-proteína D de Haemophilus influenzae.

\section{Conclusiones}

El paracetamol administrado en forma profiláctica reduce la fiebre de origen inflamatorio y las reacciones de dolor local, aunque no tiene efecto en fiebre mayor a $39^{\circ}$. Sin embargo, el uso profiláctico de paracetamol reduce significativamente la respuesta inmunogénica de varias vacunas independientemente del efecto en la fiebre.

Palabras claves: vacunación, parecetamol, antitérmicos, inmunogenicidad. Keywords: vaccination, acetaminophen, antipyretics, inmungenicity. Fuentes de financiamiento: GlaxoSmithKline Biologicals (Belgium).

\section{Comentario}

El uso de paracetamol en vacunación había sido recomendado para aquellos niños con mayor riesgo de convulsiones febriles ${ }^{1}$, aunque había advertencias de una posible disminución de la respuesta inmune ${ }^{2}$. El presente estudio, metodológicamente correcto, viene a responder una pregunta clínica muy frecuente en una población de riesgo como es la pediátrica en la que los ensayos clínicos son pocos, aunque afortunadamente en aumento. Aunque el estudio no fue cegado, la tasa de efectos adversos improbablemente afectados por el paracetamol, como diarrea, vómito y enfermedad de vía aérea superior, no difirió entre los grupos. Los investigadores demostraron que los pacientes que recibían el paracetamol en forma profiláctica tuvieron significativamente menos episodios febriles que los controles, pero la sorpresa fue que además tenían menos inmunogenicidad frente a prácticamente todas las vacunas, principalmente en la vacuna antidiftérica, antineumocóccica y antiHIB. Esta disminución en la antigenicidad genera una pregunta a nivel de la salud pública debido a que, mas allá de que la mayoría de los pacientes llegaron al nivel de seroprotección, se debería estudiar si el paracetamol disminuiría la protección clínica de la población vacunada. Las implicancias de esta pregunta son especialmente importantes en relación al HIB y al neumococo, ya que para interrumpir el estado de portador sano y la transmisión en la población general, se necesitan niveles altos y sostenidos anticuerpos ${ }^{3}$. Es importante aclarar que las vacunas utilizadas en el estudio, como por ejemplo la vacuna séxtuple, no es habitual a nivel mundial y se calcula que mas del $70 \%$ de la población mundial todavía usa la vacuna celular antidiftérica, que es mas reactogénica (fiebre y reacción local) pero no altera su inmunogenicidad en relación con el paracetamol.

Conclusiones del comentador: es preferible no realizar tratamiento profiláctico antipirético salvo que la situación lo amerite luego de evaluar en profundidad el riesgo beneficio de la práctica. Deberían realizarse estudios que evalúen también otros antipiréticos respecto de su efecto sobre la protección clínica.

Juan Tortellá [ Servicio de Medicina Familiar y Comunitaria. Hospital Italiano de Buenos Aires. juan.tortella@ hospitalitaliano.org.ar ]

Ver glosario*

Tortellá J. El uso preventivo de paracetamol reduciría la inmunogenicidad postvacunal. Evid. actual. práct. ambul; 13(1): 12, Ene-Mar.2010. Comentado de: Prymula R y col. Effect of prophylactic paracetamol administration at time of vaccination on febrile reactions and antibody responses in children: two open-label, randomised controlled trials. Lancet 2009;374:1339-50 PMID: 19837254

\section{Referencias}

1. Centers for Disease Control (CDC). Pertussis immunization; family history of convulsions and use of antipyretics—supplementary ACIP statement. MMWR Morb Mortal Wkly Rep 1987; 36: $281-82$.

2. Lewis K, Cherry JD, Sachs MH, et al. The eff ect of prophylactic acetaminophen administration on reactions to DTP vaccination. Am J Dis Child 1988; 142: 62-65.

3. McVernon J, Mitchison NA, Moxon ER. Thelper cells and effcacy of Haemophilus influenzae type b conjugate vaccine. Lancet Infect Dis 2004; 4: 40-43. 